\title{
Effects of pre-training exposure to the CS on conditioned suppression
}

\author{
R. B. MAY, C. W. TOLMAN, AND M. G. SCHOENFELDT \\ UNIVERSITY OF VICTORIA, BRITISH COLUMBIA
}

Three groups of rats were given different amounts of exposure to a tone before and during establishment of a conditioned emotional response (CER). The effectiveness of the tone as a conditioned stimulus during CER training was found to be an inverse function of the amount of experience $S$ s had had with the tone. Ss exposed to the tone only during CER training showed more conditioned suppression than $S$ s also exposed to the tone outside the test situation before and during testing.

Berlyne (1964) noted the concern of Soviet authors with the role of the orientation response to the conditioned stimulus (CS) in conditioning. The strength of this response appears to be critical in the establishment of a conditioned response. For example, on the basis of the Soviet literature, Berlyne (1964) concluded that "... if extinction of the orientation reaction to the CS has been induced before training starts, the conditioned response either fails to be formed or takes on a strange, automatized form" (p. 130). A more detailed review of this literature is now available in English (Voronin et al, 1965).

Data collected in American laboratories which bear upon this phenomenon have been reported by Lubow (Lubow, 1965; Lubow \& Moore, 1959). It was found for example that conditioned leg flexion in goats and sheep was a function of the number of presentations of the CS (light) during a $1 \mathrm{~h}$ period just prior to conditioning; Ss not exposed to the CSprior to training had a higher percentage of CRs than Ss given 20 to 40 exposures to the CS (Lubow, 1965).

A response decrement due to prior experience with the CS has also been reported by Carlton \& Vogel (1967) for a conditioned emotional response (CER). The present experiment employed a CER following the general procedures for obtaining conditioned suppression outlined by Kamin (1965). The CER phenomenon consists of the suppression of operant behavior in the presence of a warning signal (CS) which has preceded shock (US). On the basis of the above mentioned studies, it was expected that formation of a CER would be attenuated for Ss given previous experience with the to-beconditioned stimulus (CS). That is, Ss receiving such treatment should show less suppression than Ss exposed to the CS for the first time during conditioning. Subjects

The Ss were 10 male Sprague-Dawley rats approximately 120 days old at the beginning of the experiment. They were housed in pairs under conditions of $16 \mathrm{~h}$ light and $8 \mathrm{~h}$ dark and had ad lib access to water at all times in their home cages.

\section{Apparafus}

Four Grason-Stadler sound shielded operant conditioning chambers, an Eico tone generator and amplifier as well as requisite programming equipment were used. Programming, recording, and sound producing equipment were housed in a room separate from the test chambers. The ambient noise level in the chambers was $92 \mathrm{~dB}$ as measured by a scott sound level meter resting on the floor of the chamber with the door closed. Addition of a 300 cps tone, administered in the adaptation (pretest) condition and used as a CS in CER training, brought the sound level to $96 \mathrm{~dB}$ in the test chamber.

Procedure

The experiment was carried out on 33 successive days. On the first 20 days all Ss were on a $22 \mathrm{~h}$ food deprivation schedule. Maintenance diet was provided by $2 \mathrm{~h}$ ad lib feeding each day. On the last 13 days Ss were on a $21 \mathrm{~h}$ deprivation schedule since they received food reward during their $1 \mathrm{~h}$ test prior to receiving the maintenance diet.

Nine days of operant bar press training and four days of CER training followed the 20-day period of adjustment to the deprivation schedule. During the first 29 days six Ss (Group E) were housed in a room separate from the laboratory vivarium and were presented with a 1 min tone on a variable interval(VI) $10 \mathrm{~min}$ schedule $24 \mathrm{~h}$ per day. The remaining four Ss (Group C) were maintained on the deprivation schedule under "normal" laboratory conditions.

While Group E was acquiring the bar press response the tone (the to-be-conditioned stimulus in the CER phase) was presented in the test chambers on the same VI-10 schedule as used for adaptation to the tone in the home cages of this group. The acquisition phase (Days 21-29) differed for Group $C$ only in that the tone was not experienced.

All training sessions were of $1 \mathrm{~h}$ duration just prior to the $2 \mathrm{~h}$ feeding periods of the Ss. The training schedule proceeded as follows: Day 1, magazine training; Day 2, shaping of the lever response; Day 3, CRF; Days 4 and 5, reinforcement on a $1 \mathrm{~min}$ VI schedule; Days 6-9, 2-1/2 min VI schedule; Days 10-13, CER training. Ss were reinforced for the bar press response with 45 $\mathrm{mg}$ Noyes pellets. The $2-1 / 2 \mathrm{~min}$ VI food reinforcement schedule was continued through the four CER training days.

The CER training for all Ss consisted of presentation of the 1 min tone (CS), the offset of which was Immediately followed by .2 mA of scrambled shock to the 


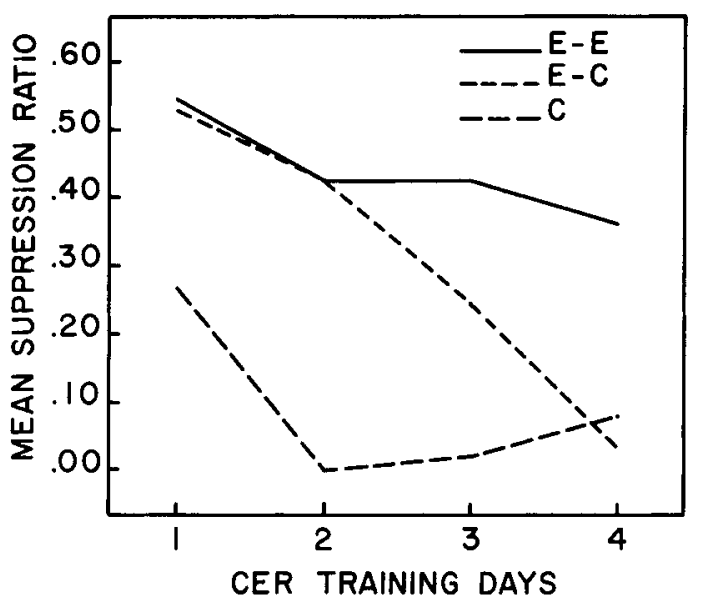

Fig. 1. Mean suppression ratios on each CER training day for groups given different amounts of exposure to the CS before and during training.

feet of $\mathrm{S}$ for $.5 \mathrm{sec}$ (US). The paired tone-shock sequence was presented on the same VI-10 min schedule as the tone alone during adaptation to the tone for Group $E$. There were six CS-UCS pairings during each of the four daily $1 \mathrm{~h}$ test periods. The first CER trial on the initial day of the CER phase was the first encounter of Group $C$ with the CS, whlle the Ss in Group E had been given adaptation to the CS for 29 days prior to the CER phase.

Following the first CER session, four of the Ss in Group $E$ were returned to the vivarium and subsequently experienced the tone only in the test chamber (Group $E-C)$. The other two Ss in Group $E$ were returned to the tone adaptation room for continued repeated presentations of the tone on the VI-10 min schedule (Group E-E). Group $\mathrm{C}$ continued to be maintained in the vivarium.

The dependent variable was a suppression ratio calculated by the formula $B / A+B$. " $B$ " represents the number of bar presses during the CS and "A" represents the number of bar presses during 1 min immediately preceding the onset of the CS. The response frequencies for each of these two periods $(1 \mathrm{~min} C S$ and $1 \mathrm{~min}$ pre-CS) were summed across the daily trials before computing the suppression ratio.

\section{Results and Discussion}

A plot of the mean suppression ratios for each of the three groups on the four CER training days is shown in Fig. 1. A treatments by days analysis of variance was carried out on these data. The analysis yielded significant treatments $(F=17.716, \mathrm{df}=2 / 7, \mathrm{p}<.005)$ and days $(F=9.908, d f=3 / 21, p<.005)$ main effects, as well as a nearly significant treatments by days interaction ( $F=2.406, d f=6 / 21, p=.066$ ).

The control group which had never been presented with the tone prior to the CER trials suppressed rapidly while the groups given previous exposure to the CS were slower to suppress. It is of interest to note that the E-E group was more retarded in the acquisition of the CER than Group E-C. This latter group showed only a modicum of suppression during the four test days.

Differences between Groups E-C and E-E might be attributed to extinction of the CS-US relationship each day in Group E-E. If one assumes that some learning did occur within a training session for Group E-E, then the subsequent presentation of the CS alone in the home cage should lead to extinction.

Alternatively, these data suggest that the relative novelty of the CS is very important in conditioning. For both Groups E-C and E-E the tone CS lacked novelty at the beginning of CER training and there was very little suppression in these groups compared to Group C. Since the recovery of an habituated orientation or exploratory response with long intersession intervals is well known (cf., Fowler, 1965, p. 54-56), one could assume that placement of the $\mathrm{E}-\mathrm{C}$ group into the vivarium without the tone after each day's testing increased the relative novelty of the tone during test sessions. Therefore, the capacity of the tone to function as a CS in the usual sense increased. As Group E-E continued to receive the tone $24 \mathrm{~h}$ per day during testing, there was little opportunity for the tone to become a novel stimulus and elicit an orientation reaction in the testing situation. Without the orientation reaction or "What is it?" response, very little, if any, learning is likely to occur.

\section{References}

BERLYNE, D. E. Emotional aspects of learning. Annu. Rev. Psychol, $1964,15,115-142$.

CARLTON, P. L., \& VOGEL, J. R. Habituation and conditioning. $J$. comp. physiol. Psychol., 1967, 63, 348-351.

FOWLER, H. Curiosity and exploratory behavior. New York: The Macmillan Company, 1965.

KAMIN, L. J. Temporal and intensity characteristics of the conditioned stimulus. In W. F. Prokasy (Ed.), Classical conditioning: A symposium. New York: Appleton-Century-Crofts, 1965. Pp. 148-171.

LUBOW, R. E. Latent inhibition: Effects of frequency nonreinforced preexposure of the CS. J. comp. physiol. Psychol., 1965, 60, 454-457.

LUBOW, R. E., \& MOORE, A. W. Latent inhibition: The effect of nonreinforced preexposure to the conditioned stimulus. J. comp. physiol. Psychol, 1959, 52, 415-419.

VORONIN, L. G., LEONTIEV, A. N., LURIA, A. R., SOKOLOV, E. N., \& VINOGRADOVA, O. S. (Eds.), Orienting reflex and exploratory behavior. Washington, D. C.: American Institute of Biological Sciences, 1965. 